\title{
Correction to: Effect of liraglutide on cardiac function in patients with type 2 diabetes mellitus: randomized placebo-controlled trial
}

Maurice B. Bizino ${ }^{1 *}$, Ingrid M. Jazet ${ }^{2}$, Jos J. M. Westenberg ${ }^{1}$, Huub J. van Eyk ${ }^{2}$, Elisabeth H. M. Paiman ${ }^{1}$, Jan W. A. Smit ${ }^{3}$ and Hildebrandus J. Lamb

\section{Correction to: Bizino et al. Cardiovasc Diabetol (2019) 18:55} https://doi.org/10.1186/s12933-019-0857-6

Following publication of the original article [1], the authors reported an error in Fig. 3. The bars in the upper right panel that represent heart rate in placebo treated patients is not correct. The revised Fig. 3 is given here.

The authors wish to apologise for this error.

\footnotetext{
*Correspondence: m.b.bizino@lumc.nl

1 Department of Radiology, Leiden University Medical Center, LUMC

postzone C2S, Albinusdreef 2, 2333 ZA Leiden, The Netherlands

Full list of author information is available at the end of the article
} 

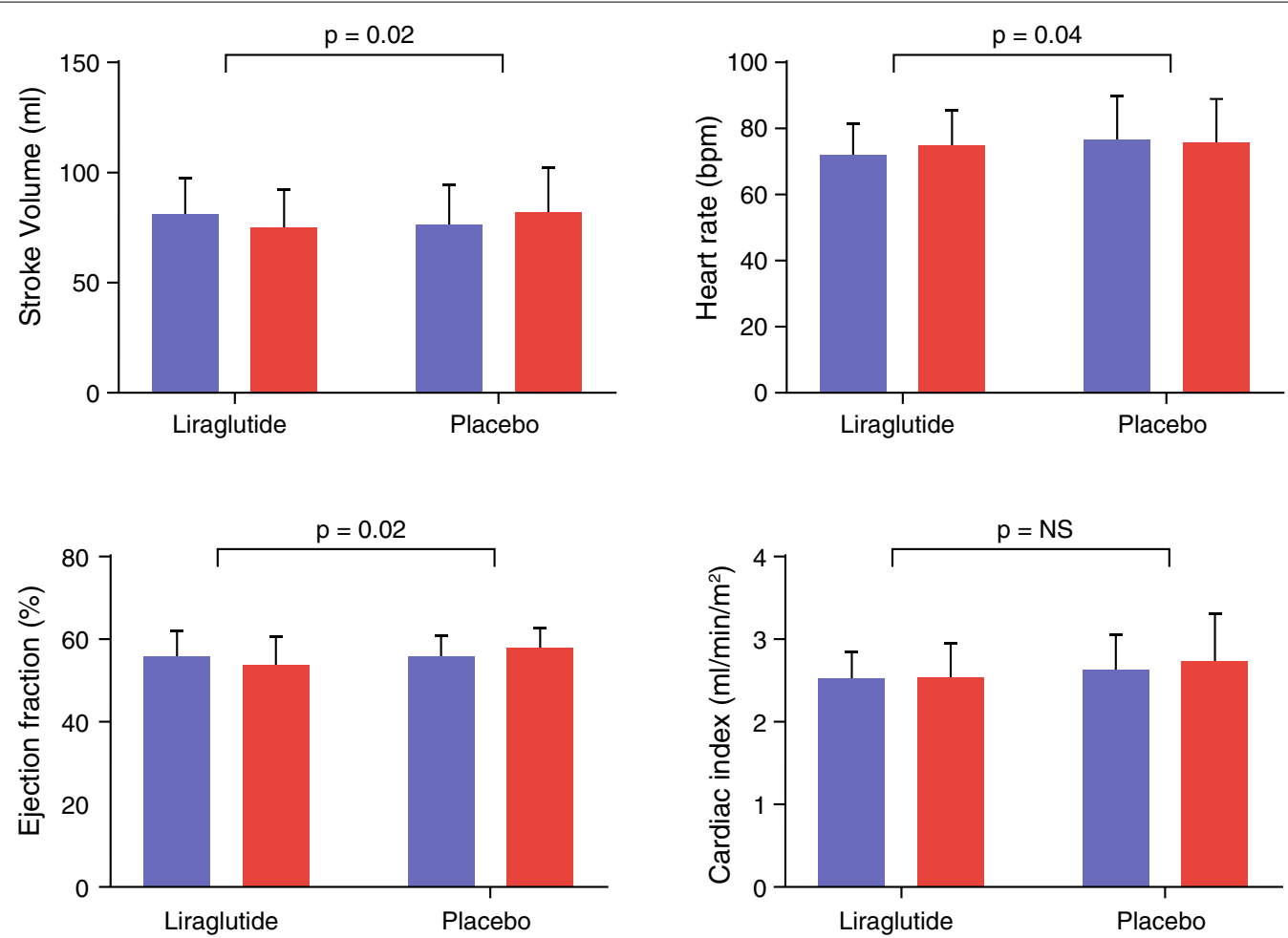

Fig. 3 LV systolic function. Bar graphs of MRI-derived indices of systolic function. Blue bars indicate baseline measurement and red bars follow-up. In the liraglutide group stroke volume decreased, whereas cardiac index remained unchanged because of the increased heart rate. Bpm beats per minute

\section{Author details}

${ }^{1}$ Department of Radiology, Leiden University Medical Center, LUMC postzone C2S, Albinusdreef 2, 2333 ZA Leiden, The Netherlands. . ${ }^{2}$ Department of Medicine, Division of Endocrinology, Leiden University Medical Center, Leiden, the Netherlands. ${ }^{3}$ Department of Medicine, Radboud University Medical Center, Nijmegen, The Netherlands.

The original article can be found online at https://doi.org/10.1186/s1293 3-019-0857-6.

\section{Reference}

1. Bizino Maurice $B$, Jazet Ingrid M, Westenberg Jos J M, van Eyk Huub J, Paiman Elisabeth H M, Smit Jan W A, Lamb Hildebrandus J. Effect of liraglutide on cardiac function in patients with type 2 diabetes mellitus: randomized placebo-controlled trial. Cardiovasc Diabetol. 2019;18:55. https://doi.org/10.1186/s12933-019-0857-6.

\section{Publisher's Note}

Springer Nature remains neutral with regard to jurisdictional claims in published maps and institutional affiliations. 